University of Nebraska - Lincoln

DigitalCommons@University of Nebraska - Lincoln

\title{
$5-2012$
}

\section{Effectiveness of Supported Employment for Veterans With Spinal Cord Injuries: Results From a Randomized Multisite Study}

\author{
Lisa Ottomanelli \\ Veterans Affairs North Texas Health Care System, lisa.ottomanelli@va.gov \\ Lance L. Goetz \\ Veterans Affairs North Texas Health Care System \\ Alina Suris \\ Veterans Affairs North Texas Health Care System \\ Charles McGeough \\ Department of Veterans Affairs Central Office \\ Patricia L. Sinnott \\ Department of Veterans Affairs
}

See next page for additional authors

Follow this and additional works at: https://digitalcommons.unl.edu/publichealthresources

Part of the Public Health Commons

Ottomanelli, Lisa; Goetz, Lance L.; Suris, Alina; McGeough, Charles; Sinnott, Patricia L.; Toscano, Rich; Barnett, Scott D.; Cipher, Daisha J.; Lind, Lisa M.; Dixon, Thomas M.; Holmes, Sally Ann; Kerrigan, Anthony J.; and Thomas, Florian P., "Effectiveness of Supported Employment for Veterans With Spinal Cord Injuries: Results From a Randomized Multisite Study" (2012). Public Health Resources. 190.

https://digitalcommons.unl.edu/publichealthresources/190

This Article is brought to you for free and open access by the Public Health Resources at DigitalCommons@University of Nebraska - Lincoln. It has been accepted for inclusion in Public Health Resources by an authorized administrator of DigitalCommons@University of Nebraska - Lincoln. 


\section{Authors}

Lisa Ottomanelli, Lance L. Goetz, Alina Suris, Charles McGeough, Patricia L. Sinnott, Rich Toscano, Scott D. Barnett, Daisha J. Cipher, Lisa M. Lind, Thomas M. Dixon, Sally Ann Holmes, Anthony J. Kerrigan, and Florian P. Thomas 


\title{
Effectiveness of Supported Employment for Veterans With Spinal Cord Injuries: Results From a Randomized Multisite Study
}

\author{
Lisa Ottomanelli, PhD, Lance L. Goetz, MD, Alina Suris, PhD, Charles McGeough, MS, \\ Patricia L. Sinnott, PhD, Rich Toscano, MEd, Scott D. Barnett, PhD, Daisha J. Cipher, PhD, \\ Lisa M. Lind, PhD, Thomas M. Dixon, PhD, Sally Ann Holmes, MD, Anthony J. Kerrigan, PhD, \\ Florian P. Thomas, MD
}

ABSTRACT. Ottomanelli L, Goetz LL, Suris A, McGeough C, Sinnott PL, Toscano R, Barnett SD, Cipher DJ, Lind LM, Dixon TM, Holmes SA, Kerrigan AJ, Thomas FP. Effectiveness of supported employment for veterans with spinal cord injuries: results from a randomized multisite study. Arch Phys Med Rehabil 2012;93:740-7.

Objective: To examine whether supported employment (SE) is more effective than treatment as usual (TAU) in returning veterans to competitive employment after spinal cord injury (SCI).

Design: Prospective, randomized, controlled, multisite trial of SE versus TAU for vocational issues with 12 months of follow-up data.

Setting: SCI centers in the Veterans Health Administration.

Participants: Subjects $(\mathrm{N}=201)$ were enrolled and completed baseline interviews. In interventional sites, subjects were randomly assigned to the SE condition $(n=81)$ or the TAU condition (treatment as usual-interventional site [TAU-IS], $\mathrm{n}=76$ ). In observational sites where the SE program was not available, 44 subjects were enrolled in a nonrandomized TAU condition (treatment as usual-observational site [TAU-OS]).

Interventions: The intervention consisted of an SE vocational rehabilitation program called the Spinal Cord Injury Vocational Integration Program, which adhered as closely as possible to principles of SE as developed and described in the individual

From the Veterans Affairs (VA) North Texas Health Care System, Dallas, TX (Ottomanelli, Goetz, Suris); Departments of Physical Medicine and Rehabilitation (Ottomanelli, Goetz) and Psychiatry (Suris, Lind), University of Texas Southwestern Medical School, Dallas, TX; Compensated Work Therapy, Department of Veterans Affairs Central Office, Washington, DC (McGeough, Toscano); Health Economics Resource Center, Department of Veterans Affairs, Palo Alto, CA (Sinnott); Health Service Research and Development (HSR\&D)/Rehabilitation Research and Development (RR\&D) Center of Excellence Maximizing Rehabilitation Outcomes, James A. Haley Veterans Hospital, Tampa, FL (Barnett, Ottomanelli); College of Nursing, University of Texas at Arlington, Arlington, TX (Cipher); Louis Stokes VA Medical Center, Cleveland, OH (Dixon); Michael E. DeBakey Veterans Affairs Medical Center (VAMC), and Department of Physical Medicine And Rehabilitation, Baylor College of Medicine, Houston, TX (Holmes, Kerrigan); St. Louis VA Medical Center and the Department of Neurology \& Psychiatry, Saint Louis University, St. Louis, MO (Thomas).

Supported by the Office of Research and Development, Rehabilitation Research and Development Service, Department of Veterans Affairs (VA RR\&D grant no. B3773R).

Contents of this article do not represent the views of the Department of Veterans Affairs or the United States Government.

No commercial party having a direct financial interest in the results of the research supporting this article has or will confer a benefit on the authors or on any organization with which the authors are associated.

Clinical Trial Registration No.: NCT00117806.

Correspondence to Lisa Ottomanelli, PhD, James A. Haley VAMC, 8900 Grand Oak Circle, Tampa, FL 33637, e-mail: lisa.ottomanelli@va.gov. Reprints are not available from the author.

0003-9993/12/9305-01083\$36.00/0

doi:10.1016/j.apmr.2012.01.002 placement and support model of SE for persons with mental illness.

Main Outcome Measures: The primary study outcome measurement was competitive employment in the community.

Results: Subjects in the SE group were 2.5 times more likely than the TAU-IS group and 11.4 times more likely than the TAU-OS group to obtain competitive employment.

Conclusions: To the best of our knowledge, this is the first and only controlled study of a specific vocational rehabilitation program to report improved employment outcomes for persons with SCI. SE, a well-prescribed method of integrated vocational care, was superior to usual practices in improving employment outcomes for veterans with SCI.

Key Words: Employment, supported; Rehabilitation; Rehabilitation, vocational; Spinal cord injuries; Veterans.

(C) 2012 by the American Congress of Rehabilitation Medicine

$\mathbf{U}$ NEMPLOYMENT IS A SERIOUS and prevalent problem among persons with physical disabilities such as spinal cord injury (SCI). Reviews of the literature indicate that the average rate of any paid employment for individuals after $\mathrm{SCI}$ is approximately $35 \%,{ }^{1}$ as compared with $79 \%$ for individuals without disabilities in the United States. ${ }^{2}$ It has been estimated that only $12 \%$ of individuals with SCI return to their preinjury jobs. $^{3}$ These low employment rates after SCI are evident among both community and veteran samples. ${ }^{1,4-7}$ Most unemployed persons with disabilities report that they want to work,

\section{List of Abbreviations}

\begin{tabular}{|c|c|}
\hline AIS & $\begin{array}{l}\text { American Spinal Injury Association Impairment } \\
\text { Scale }\end{array}$ \\
\hline ASIA & American Spinal Injury Association \\
\hline $\mathrm{Cl}$ & confidence interval \\
\hline CWT & compensated work therapy \\
\hline EBP-SE & evidence-based practice supported employment \\
\hline IPS & individual placement and support \\
\hline $\mathrm{SCl}$ & spinal cord injury \\
\hline SCI-VIP & $\begin{array}{l}\text { Spinal Cord Injury Vocational Integration } \\
\text { Program }\end{array}$ \\
\hline SE & supported employment \\
\hline SMI & serious mental illness \\
\hline TAU & treatment as usual \\
\hline TAU-IS & treatment as usual-interventional site \\
\hline TAU-OS & treatment as usual-observational site \\
\hline VA & Veterans Affairs \\
\hline VAMC & Veterans Affairs Medical Center \\
\hline VR & vocational rehabilitation \\
\hline
\end{tabular}


and data suggest that many persons with SCI who are currently unemployed judge themselves to be capable of working ${ }^{8}$ and express a desire to work. ${ }^{9}$ Low employment rates after rehabilitation are cause for concern, since return to gainful employment may be the most recognized primary marker of successful rehabilitation outcome after disability. ${ }^{10}$ Characteristics associated with employment after SCI include demographic variables (education, sex, race, marital status), injury-related factors (age at injury, level of injury/impairment/functional status, time since injury), employment history (employment at or before injury), psychosocial issues (transportation, physical health, life satisfaction, locus of control, motivational level/ expectation to work, social support), and disability benefit status. ${ }^{1}$ Generally, those who are younger at the time of the injury, have a higher education level, have a less severe injury, and were employed before the injury tend to have better postinjury employment outcomes.

The Rehabilitation Act of 1986, along with its 1992 amendment, included provisions for supported employment (SE) to promote inclusion in the workplace of persons with disabilities. ${ }^{11,12}$ In practice, the generic term SE refers to a number of broad approaches that involve ongoing supportive services designed to engage competitive employment among individuals with severe disabilities who have experienced a loss of employment because of disability, or never experienced competitive employment, but want to work. Historically, such approaches have been applied to assist persons with intellectual or cognitive disabilities, and they have increasingly been used to serve persons with other disabilities in recent times. Since SCI is not treated as a separate category in published data reports, it is difficult to discern the prevalence of its use among this population. Although widely used in various community settings, SE strategies practiced in a generic fashion are distinct from the evidenced-based practice model of SE.

Evidence-based practice SE (EBP-SE), also known as the individualized placement and support (IPS) model, is a vocational rehabilitation (VR) modality that promotes high levels of integration with the clinical team to help people obtain and maintain community-based competitive employment in their chosen occupation. ${ }^{13-15}$ This model follows well-defined principles that essentially standardize SE procedures, measurement, and research practices in the field. To date, it has only been applied to assist people with serious mental illness in both the general and veteran populations. In a review of randomized controlled trials of EBP-SE, Bond et $\mathrm{al}^{16}$ concluded that EBP$\mathrm{SE}$, when provided with moderate to high adherence to the core principles, shows evidence of being one of the most robust employment interventions available for persons with serious mental illness (SMI). Such reviews of controlled studies have shown competitive employment rates for individuals with SMI who received EBP-SE in the $40 \%$ to $60 \%$ range, compared with $20 \%$ for those not in EBP-SE programs. ${ }^{13,15}$ In 2004, the Veterans Health Administration implemented a large-scale initiative to provide evidenced-based SE to veterans with SMI under the auspices of the Office of Mental Health/Compensated Work Therapy (CWT) Programs. ${ }^{17}$ To our knowledge, there are no published outcomes from controlled clinical trials of EBP-SE among veterans. There is a report of a modest increase in employment rates among homeless veterans with psychiatric and substance abuse disorders after implementation of an SE program at several Veterans Affairs Medical Centers (VAMCs). ${ }^{18}$ The low effect size $(15 \%)$ seen in this study has been attributed to possible methodological issues or program issues, such as the presence of a competing model of transitional work, that may have resulted in lower fidelity in implementing $\mathrm{SE}$ in this population. ${ }^{19}$
At the present time, there are no controlled outcome studies on the effectiveness of any type of VR interventions after SCI. There are published case reports documenting various work supports that have been used successfully to reduce barriers and return individuals with SCI to work. ${ }^{20-22}$ There are no studies reporting the use of the evidence-based model of SE or IPS among persons with SCI.

The purpose of the current study was to examine whether SE following evidence-based principles is more effective than standard care (conventional VR through referrals) in helping persons with SCI return to competitive employment. To the best of our knowledge, this is the first prospective, multisite, randomized controlled trial of SE versus standard VR care in a population of veterans with SCI. To our knowledge, this study is also the only project to translate evidence-based SE into a population with physical disabilities and the first study to apply $\mathrm{SE}$ procedures to help veterans with SCI return to work.

\section{METHODS}

\section{Participants and Settings}

Participants consisted of veterans with SCI between the ages of 18 and 65 years who received medical and/or rehabilitation health care services in the SCI centers at 1 of 6 participating VAMCs. Consideration of a wide variety of factors was used in selecting sites, such as location in a metropolitan geographic region, adequate economic and industrial development, strong management and leadership support at the local medical center, available subject pool, and existing public transportation systems. Each participating site obtained approval of its respective institutional review board. Only veterans who were not employed, or were employed but not at a substantial income level (defined as earning less than Social Security's definition of substantial gainful activity) were eligible to participate in the study. Veterans who had gainful employment at the time of study enrollment were excluded from the study.

\section{Design}

Methods of this clinical trial have been described in depth elsewhere. ${ }^{23}$ In brief, at interventional sites, subjects were randomly assigned using a biased coin design ${ }^{24}$ without stratification or adjustment to either SE or treatment as usualinterventional site (TAU-IS). At observational sites, the SE condition was not available, and all subjects received treatment as usual-observational site (TAU-OS). All study subjects provided written informed consent before enrollment. Baseline assessments were conducted after enrollment and randomization.

Our primary hypothesis was as follows: SE will improve competitive employment outcomes and general rehabilitation outcomes significantly more than conventional VR (ie, standard care) among veterans with SCI.

\section{Treatment Conditions}

Subjects in the SE condition received the IPS model of SE. Since the model is considered disability neutral, it was implemented in this population without any modifications. Hence, the study sought to follow the evidence-based principles of SE as closely as possible including integrated vocational and medical rehabilitation treatment, rapid engagement in job finding, competitive employment, inclusion regardless of severity or type of disability, ongoing job support, and focus on participant preferences. Services were primarily provided in the community, rather than in office or hospital settings, and access to personalized benefits counseling was included. The provision 
of these services was by a VR counselor who was hired for the study, trained in the IPS SE model, and integrated as a provider among the SCI interdisciplinary care team in the SCI center. The treatment-as-usual (TAU) condition typically involved referrals to VR services outside the Veterans Affairs (VA) SCI center. In this condition, there was not a single provider of VR services who was part of the SCI interdisciplinary care team at the SCI center. Rather, subjects in the TAU condition were referred by the research coordinator back to their clinical SCI interdisciplinary team members (eg, physiatrist, psychologist, social worker) who would provide them with a referral to an agency or provider who was not part of the SCI center (eg, state VR), and these subjects may or may not have received any additional VR services.

\section{Procedures}

Potential participants were referred by SCI treatment providers or self-referred after reading institutional review boardapproved study advertising materials. The research coordinator at the participating VAMC met with each referral to review the study and obtain informed consent. Subjects drawn from the interventional sites who met inclusion criteria were randomly assigned to either SE or the comparison group. Veterans who receive health care from the observational sites and met inclusion criteria were not randomly assigned but were asked to participate as comparison-group subjects.

The study was open for enrollment of new subjects for a 3-year period. Once enrolled, all subjects were followed up for 12 months, during which time quarterly face-to-face interviews were conducted by the research coordinator to collect data on both primary employment variables and secondary outcomes measures. Research coordinators and clinical staff were not blinded to treatment condition. Coordinators participated in an intensive 3-day training course on study measures and procedures at study initiation, and in 3 additional training workshops throughout the course of the study, as well as weekly and monthly study conference calls where measurement issues were discussed and reviewed.

All participants were referred for benefits counseling on enrolling in the study. Social Security benefits information was available through local Work Incentive Planning and Assistance projects, and veterans benefits information was made available through Paralyzed Veterans of America National Service Officers at the local VAMC SCI centers. These referrals allowed participants the opportunity to learn about their current benefits, understand the role of work incentives and protections of disability benefits, and evaluate the impact that employment could have on their disability benefits. Veterans were notified that their VA benefits are protected while participating in CWT SE.

\section{Primary Endpoint}

The primary endpoint was competitive employment, meaning a paying job earning at least minimum wage in the community. Volunteer work and sheltered employment did not qualify as employment for the purposes of the present study.

\section{Measures}

The following data were obtained through subject interviews and chart extraction: sociodemographics (self-reported race/ ethnicity, sex, date of birth, educational level), date of the SCI, medical and psychiatric comorbidities, financial information, employment history, VA and Social Security benefits information, and health, social, vocational, functional, and psychological issues as assessed by the Veterans RAND 36-Item Health
Survey, ${ }^{25}$ Quick Inventory for Depressive SymptomatologySelf-Report, ${ }^{26}$ and Craig Handicap Assessment and Reporting Technique. $^{27}$

The IPS Fidelity Scale ${ }^{28}$ was used to measure the adherence to the SE model. The Fidelity Scale is a 15 -item instrument that divides into 3 subdivisions (staffing, organization, services) to assess several domains of SE. Each item was rated on a scale of 1 to 5 , with higher numbers indicative of criterion SE. The total score for the scale is calculated by summing the item values, for a maximum value of 75 . Bond et $\mathrm{al}^{29}$ determined that programs scoring greater than 65 are consistent with IPS (good implementation), those scoring between 56 and 65 are partially consistent with IPS (fair implementation), and those scoring less than 56 are not IPS programs (not SE). The published internal consistency coefficient for the whole instrument is .83, and the 4 subscales' coefficients have ranged from .55 to $.70 .^{29}$ Reviews were conducted every 6 months at each study site by experts in the tenets of evidence-based SE.

\section{Power Analysis}

Power analyses performed before study commencement indicated that a total of 126 subjects completing the study provided at least $80 \%$ power to address our primary research objective using logistic regression analysis of our primary study outcome, employment. This sample size estimate was based on a moderate effect size (odds ratio=2.0), $\alpha$ of .05 , 2-tailed.

\section{Statistical Analysis}

Continuous parameters were reported as mean $\pm \mathrm{SD}$, and discrete parameters were reported as a percentage. Data were explored for departures from normality by standard descriptive statistics. In the event data were observed to not reflect a normal distribution, group comparisons were made with the Student $t$ test or Wilcoxon rank-sum tests with normal approximation, where appropriate, for continuous data, and the Pearson chi-square test or Fisher exact test, where appropriate, for categorical data. Rates of competitive employment are presented as percent employed per group with $95 \%$ Wald confidence intervals (CIs) with normal approximation, and were performed with an intent-to-treat approach-all randomly assigned subjects for whom data are available contributed to employment analyses. For the analysis of employment characteristics (wages, time worked), the sample was restricted to those subjects who obtained competitive or any type of paid employment. Rate ratios and 95\% CIs were calculated using conditional maximum likelihood. Effect sizes calculated for employment outcome data included rate ratios, and Cohen's $d$ for continuous data, and Cramer's $\nu$ for categorical data, where appropriate. All analyses were performed with SAS version 9.2.

\section{RESULTS}

\section{Participant Characteristics}

A total of 201 subjects, with a mean age \pm SD of $48.3 \pm 9.9$ years, were enrolled and completed baseline and 1-year follow-up interviews in the SCI VocationaI Integration Program (SCI-VIP) study. During the course of the study, there were 3 interventional sites and 3 observational sites that contributed subjects, with enrollment that ranged from 6 to 65 subjects per site depending on the period the site was open for enrollment. The characteristics of the study sample are shown in table 1. Subjects were primarily men $(n=192,95.5 \%)$, and half were white $(50 \%, n=100)$, followed by African American $(n=77$, 
Table 1: Demographic Characteristics at Baseline $(\mathrm{N}=\mathbf{2 0 1})$

\begin{tabular}{lccc}
\hline \multicolumn{1}{c}{ Characteristics } & $\begin{array}{c}\text { SE } \\
(\mathrm{n}=81)\end{array}$ & $\begin{array}{c}\text { TAU-IS } \\
(\mathrm{n}=76)\end{array}$ & $\begin{array}{c}\text { TAU-OS } \\
(\mathrm{n}=44)\end{array}$ \\
\hline Age (y) & $48.7 \pm 9.8$ & $49.8 \pm 9.8$ & $45.1 \pm 9.9$ \\
Education (y) & $13.1 \pm 2.3$ & $13.5 \pm 1.9$ & $13.5 \pm 1.9$ \\
Race & & & \\
$\quad$ White & $37(45.7)$ & $33(43.4)$ & $30(68.2)$ \\
$\quad$ African American & $29(35.8)$ & $37(48.7)$ & $11(25.0)$ \\
$\quad$ Hispanic & $5(6.2)$ & $1(1.3)$ & $2(4.6)$ \\
$\quad$ Other & $10(12.3)$ & $5(6.6)$ & $1(2.2)$ \\
Marital status & $30(37.0)$ & $15(19.7)$ & $9(20.5)$ \\
$\quad$ Married & $28(34.6)$ & $34(44.7)$ & $23(52.3)$ \\
$\quad$ Divorced & $23(28.4)$ & $27(35.5)$ & $12(27.3)$ \\
$\quad$ Other & $50(61.7)$ & $43(56.6)$ & $23(52.3)$ \\
VA benefits & & & \\
Service-connected & $19(23.8)$ & $15(19.7)$ & $15(34.1)$ \\
$\quad$ benefits for SCI & & & \\
$\quad$ If yes, service & $16(76.2)$ & $13(86.8)$ & $12(92.3)$ \\
$\quad$ connected 100\% & $26(32.1)$ & $20(26.3)$ & $10(22.7)$ \\
No SC/NSC SCI benefits & & & \\
Non-service-connected & $18(22.2)$ & $18(23.7)$ & $5(11.9)$ \\
$\quad$ pension & $1024 \pm 482$ & $986 \pm 421$ & $530 \pm 625^{*}$ \\
Monthly NSC amount $\$ \$)$ & $10(11.9)$ & $11(14.5)$ & $5(11.9)$ \\
SSI & $45(53.6)$ & $46(60.5)$ & $30(71.4)$ \\
SSDI & $26(32.1)$ & $20(26.3)$ & $10(22.77)$ \\
Neither SSI/SSDI & &
\end{tabular}

NOTE. Values are mean \pm SD or $\mathrm{n}(\%)$. Reported statistic is a result of either Student $t$ test or $\chi^{2}$.

Abbreviations: NSC, non-service-connected; SC, service-connected; SSDI, Social Security Disability Insurance; SSI, Supplemental Security Income.

* Statistically significant association between SE and TAU-OS $(P<.05)$.

$38.0 \%)$ and Hispanic $(n=8,4.0 \%)$. Subjects had a mean \pm SD of $13.4 \pm 2.2$ years of education, and they had sustained their SCI a mean \pm SD of $12.4 \pm 11.2$ years before enrollment. Eighty-five (43\%) of the subjects were divorced, $54(26.7 \%)$ were married, 39 (19.3\%) were never married, and the remaining $23(11.4 \%)$ were either separated, widowed, or cohabitating.

Twenty-six (13\%) subjects in the sample received Supplemental Security Income, and 120 (59.9\%) received Social Security disability insurance. More than half of the study sample received VA benefits $(n=116,57.4 \%)$, and of those subjects, $97(83.7 \%)$ received service-connected benefits. Among those receiving VA benefits, 49 (42.2\%) were receiving service-connected benefits for SCI, and $9(7.8 \%)$ were receiving service-connected benefits for individual unemployability. Among subjects receiving VA benefits, $41(35.3 \%)$ reported receiving a non-service-connected pension. No subjects were competitively employed at baseline. There were 2 subjects with noncompetitive employment at baseline (transitional work experience and sheltered workshop).

Almost half the sample had paraplegia $(n=95,47.3 \%)$, with the remainder having either high $(\mathrm{C} 1-4)$ tetraplegia $(n=69$, $34.3 \%)$ or low $(\mathrm{C} 5-8)$ tetraplegia $(n=33,16.4 \%)$. The American Spinal Injury Association (ASIA) uses an international classification rating system, the ASIA Impairment Scale (AIS), to categorize SCIs in terms of the amount of sensation and motor strength. ${ }^{30}$ Most subjects were classified as being "complete" on the ASIA scale, meaning no motor strength or sensation (AIS A; $n=66,33.3 \%$ ), followed by motor incompletehigh muscle strength (AIS D; $\mathrm{n}=58,29.2 \%$ ), motor incomplete-low muscle strength (AIS C; $\mathrm{n}=37,18.3 \%$ ), sensory incomplete (AIS B; $n=27,13.4 \%$ ), and normal (AIS E; $\mathrm{n}=10,5.0 \%)$. When ASIA ratings and neurologic levels were combined to reflect varying impairment levels, 35 subjects $(17.3 \%)$ in the sample had high tetraplegia with an AIS of A, $\mathrm{B}$, or $\mathrm{C} ; 19$ subjects $(9.4 \%)$ in the sample had low tetraplegia with an AIS of A, B, or C; $77(38.1 \%)$ had paraplegia with an AIS of A, B, or C; and $68(34.2 \%)$ were AIS D or E regardless of neurologic level (table 2).

More than one third of the subjects' SCIs were caused by a motor vehicle collision $(n=79,39.1 \%)$, followed by a gunshot wound $(n=33,16.3 \%)$ or a fall $(n=28,14.9 \%)$. Co-occurring injuries and comorbidities were categorized according to published examples from the National Institute on Disability and Rehabilitation Research SCI Model Systems. ${ }^{31}$ Coinjuries associated with SCI included fractures $(n=45,22.3 \%)$, loss of consciousness $(n=36,17.8 \%)$, and head injuries $(n=30$, $14.9 \%)$. The most common medical comorbidities were hypertension $(n=58,28.7 \%)$ and diabetes mellitus $(n=28,13.9 \%)$. The most common psychiatric comorbidities were depression $(\mathrm{n}=65,32.2 \%)$ and substance abuse or dependence $(\mathrm{n}=57$, $28.2 \%)$

\section{Fidelity Assessments}

The 3 SCI-VIP sites providing SE were evaluated every 6 months using the 15-item IPS Fidelity Scale. No differences in

Table 2: Clinical Characteristics at Baseline $(\mathrm{N}=201)$

\begin{tabular}{|c|c|c|c|}
\hline Characteristics & $\begin{array}{c}\mathrm{SE} \\
(\mathrm{n}=81)\end{array}$ & $\begin{array}{l}\text { TAU-IS } \\
(n=76)\end{array}$ & $\begin{array}{c}\text { TAU-OS } \\
(n=44)\end{array}$ \\
\hline \multicolumn{4}{|l|}{ Cause of injury } \\
\hline Motor vehicle collision & $30(35.0)$ & $28(36.8)$ & $21(48.8)$ \\
\hline Fall & $14(17.3)$ & $9(11.8)$ & $5(11.9)$ \\
\hline Gunshot wound & $15(18.5)$ & $12(15.8)$ & $6(14.0)$ \\
\hline Average time since injury $(y)$ & $10.7 \pm 11.3$ & $12.4 \pm 11.6$ & $15.2 \pm 10.2^{*}$ \\
\hline FIM total & $98.9 \pm 23.8$ & $98.2 \pm 23.7$ & $101.0 \pm 27.3$ \\
\hline \multicolumn{4}{|l|}{ AIS } \\
\hline A & $26(32.5)$ & $20(26.3)$ & $22(50.0)^{*}$ \\
\hline $\mathrm{B}$ & $11(13.8)$ & $13(17.1)$ & $3(6.8)$ \\
\hline $\mathrm{C}$ & $18(22.5)$ & $18(23.7)$ & $1(2.3)$ \\
\hline $\mathrm{D}$ & $25(31.3)$ & $21(27.6)$ & $12(27.3)$ \\
\hline $\mathrm{E}$ & $0(0.0)$ & $4(5.3)$ & $6(13.6)$ \\
\hline \multicolumn{4}{|l|}{ AIS and neurologic level } \\
\hline High tetraplegia, AIS A, B, C & $12(15.0)$ & $13(17.1)$ & $10(22.7)$ \\
\hline Low tetraplegia, AIS A, B, C & $5(6.3)$ & $10(13.2)$ & $4(9.1)$ \\
\hline Paraplegia, AIS A, B, C & $38(47.5)$ & $27(35.5)$ & $12(27.7)$ \\
\hline AIS D/E & $25(31.3)$ & $25(32.9)$ & $18(40.9)$ \\
\hline \multicolumn{4}{|l|}{ Medical comorbidities } \\
\hline Hypertension & $26(32.1)$ & $22(28.9)$ & $10(23.3)$ \\
\hline Cervical spondylosis & $8(9.9)$ & $7(9.2)$ & $0(0.0)$ \\
\hline Heart disease & $4(4.9)$ & $5(6.6)$ & $2(4.8)$ \\
\hline Degenerative joint disease & $4(4.9)$ & $5(6.6)$ & $2(4.7)$ \\
\hline Spinal canal stenosis & $14(17.3)$ & $11(14.5)$ & $2(4.7)$ \\
\hline COPD & $2(2.5)$ & $1(1.3)$ & $2(4.7)$ \\
\hline Diabetes & $13(16.1)$ & $12(15.8)$ & $3(7.0)$ \\
\hline None of above & $43(53.1)$ & $38(50.0)$ & $23(53.5)$ \\
\hline \multicolumn{4}{|l|}{ Mental health comorbidities } \\
\hline Depression & $28(34.6)$ & $26(34.2)$ & $11(25.0)$ \\
\hline Bipolar disorder & $1(1.2)$ & $0(0.0)$ & $1(2.3)$ \\
\hline Substance abuse & $23(28.4)$ & $24(31.6)$ & $10(22.7)$ \\
\hline Anxiety disorder & $1(1.2)$ & $3(3.9)$ & $0(0.0)$ \\
\hline
\end{tabular}

NOTE. Values are mean \pm SD or $\mathrm{n}(\%)$.

Abbreviation: COPD, chronic obstructive pulmonary disease.

${ }^{*}$ Statistically significant association between SE and TAU-OS $\left(\chi^{2}\right.$, $P<.05)$. 


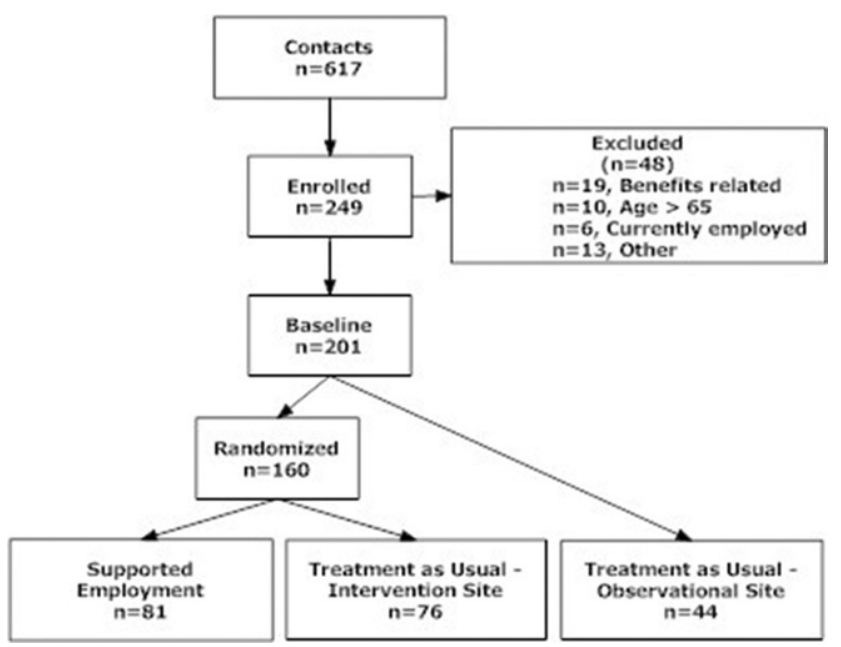

Fig 1. Consolidated Standards of Reporting Trials graph.

Fidelity scores over time or between sites in these biannual visits were observed during the study period $\left(\mathrm{F}_{7,18}=0.8\right.$, $P<.619$; range, 59-68). A review of each site's fidelity ratings suggests significant achievement toward good SE implementation. As a whole, site fidelity scores averaged 63.4 \pm 2.5 , which falls within the upper portion of the "fair" range. Fidelity scores for staffing (12.8 \pm 0.5$)$, organization (11.6 \pm 1.6$)$, and services $(38.9 \pm 1.5)$ demonstrated little change over the study period.

\section{Randomization and Attrition}

Of the 201 subjects who completed baseline and follow-up interviews, $81(40.3 \%)$ were randomly assigned to the SE group, $76(37.8 \%)$ were randomly assigned to the TAU-IS group, and $44(21.9 \%)$ were in the TAU-OS group (fig 1). Subjects in all 3 conditions reported at least 1 visit with a VR provider. Subjects in the SE group had an average of $3.5 \mathrm{VR}$ provider visits, and subjects in the TAU-IS and TAU-OS conditions had an average of 1.3 and $1.6 \mathrm{VR}$ visits, respectively. Retention by site at 1 year ranged from $67 \%$ to $97 \%$, with higher enrolling sites experiencing the least attrition.

Subject attrition was defined as any subject who either officially dropped out of the study or did not complete the

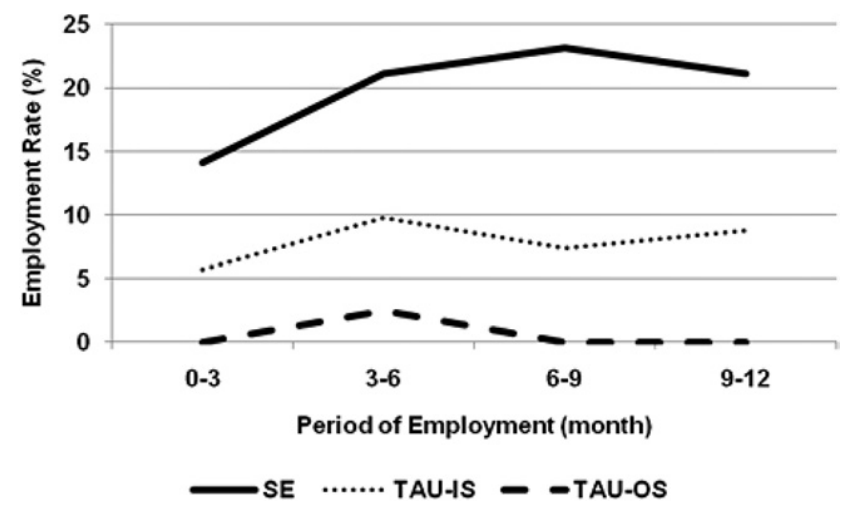

Fig 2. Twelve-month employment rates during year 1.

12-month interview. For the first 12 months of the study, the attrition rate was $12.4 \%(25 / 201)$. Of the 25 subjects who did not complete the first year of study participation, the reasons for study withdrawal were early exit/loss to follow-up $(n=16$, $64.0 \%)$, followed by withdrawal by investigator $(n=5,20.0 \%)$ and subject withdrew $(n=4,16.0 \%)$. Attrition among SE subjects $(n=14,17.3 \%)$ was significantly higher when compared with TAU-IS subjects $(\mathrm{n}=7,9.2 \% ; P<.138)$ but not the TAU-OS group $(\mathrm{n}=4,9.5 \% ; P<.183)$.

\section{Comparison of Treatment Groups on Employment}

Our primary outcome variable, employment, was defined as competitive employment obtained after the baseline interview. Employment rates are presented in table 3 for subjects completing year 1 . Among the 201 subjects, 35 subjects $(17.4 \%)$ accounted for 90 total jobs. The rate of employment for SE subjects was significantly greater $(29.6 \%$; 95\% CI, 20.8-40.4) than that of either the TAU-IS group $(11.8 \%$; $95 \% \mathrm{CI}, 4.6-$ $19.1 ; P<.003)$ or the TAU-OS group $(4.8 \% ; 95 \% \mathrm{CI}, 0.5-16.7$; $P<.002)$. When employment was restricted to competitive employment only, SE subjects significantly accounted for 50 $(69.4 \%)$ of 72 jobs and were significantly more likely to achieve employment (25.9\%; 95\% CI, 17.6-36.5) compared with either TAU-IS subjects (10.5\%; 95\% CI, 3.6-17.4; $P<.008)$ or TAU-OS subjects $(2.3 \% ; 95 \% \mathrm{CI}, 0.0-12.9$; $P<$.002) (see table 3; fig 2).

Table 3: Employment Rates During Year 1 Among Those Subjects Obtaining Employment

\begin{tabular}{|c|c|c|c|}
\hline Variable & $\begin{array}{c}\mathrm{SE} \\
(\mathrm{n}=81)\end{array}$ & $\begin{array}{l}\text { TAU- IS } \\
(n=76)\end{array}$ & $\begin{array}{c}\text { TAU-OS } \\
(n=44)\end{array}$ \\
\hline \multicolumn{4}{|l|}{ Overall employment } \\
\hline Total jobs & 60 (NA) & 28 (NA) & 2 (NA) \\
\hline Unique subjects with job & $24(29.6)$ & $9(11.8)^{*}$ & $2(4.8)^{\dagger}$ \\
\hline Employment rate & $29.6(20.8-40.4)$ & $11.8(4.6-19.1)^{*}$ & $4.8(0.5-16.7)^{\dagger}$ \\
\hline Rate ratio & NA & $2.5(1.2-5.7)^{*}$ & $6.5(1.8-40.9)^{\dagger}$ \\
\hline \multicolumn{4}{|l|}{ Competitive employment } \\
\hline Total jobs & 50 (NA) & 21 (NA) & 1 (NA) \\
\hline Unique subjects with job & $21(25.9)$ & $8(3.6)^{*}$ & $1(2.3)^{\dagger}$ \\
\hline Employment rate & $25.9(17.6-36.5)$ & $10.5(3.6-17.4)^{*}$ & $2.3(0.0-12.9)^{\dagger}$ \\
\hline Rate ratio & NA & $2.5(1.1-5.9)^{*}$ & $11.4(2.1-238.4)^{\dagger}$ \\
\hline
\end{tabular}

NOTE. Values are $\mathrm{n}(\%)$ or rate ratio $(95 \% \mathrm{Cl})$ for the comparison of SE vs TAU-IS and SE vs TAU-OS. No percentages (NA) are given for Total jobs, as subjects were allowed to have multiple jobs and there is no expressed denominator.

Abbreviation: NA, not applicable.

* Statistically significant association between SE and TAU-IS $\left(\chi^{2}, P<.05\right)$.

${ }^{+}$Statistically significant association between SE and TAU-OS $\left(\chi^{2}, P<.05\right)$. 
Table 4: Employment Characteristics During Year 1 Among Those Participants Obtaining Overall Employment

\begin{tabular}{|c|c|c|c|}
\hline Employment Characteristics & $\begin{array}{c}S E \\
(n=24) \\
M e a n \pm S D\end{array}$ & $\begin{array}{c}\text { TAU-IS } \\
(\mathrm{n}=9) \\
\text { Mean } \pm \mathrm{SD}(d)\end{array}$ & $\begin{array}{c}\text { TAU-OS } \\
(n=2) \\
\text { Mean } \pm \mathrm{SD}(d)\end{array}$ \\
\hline Total jobs & 60 (NA) & 28 (NA) & 2 (NA) \\
\hline Length of employment (wk) & $17.3 \pm 13.1$ & $24.8 \pm 16.0 *(-.51)$ & $6.1 \pm 3.8^{\dagger}(-.51)$ \\
\hline Wages per week (\$) & $233.9 \pm 279.0$ & $267.3 \pm 462.5^{*}(-.09)$ & $150.0 \pm 0.0(.43)$ \\
\hline Hours worked per week & $22.0 \pm 14.6$ & $17.0 \pm 14.6 *(.34)$ & $16.0 \pm 0(0.58)$ \\
\hline Days worked per week & $3.3 \pm 1.8$ & $3.3 \pm 1.8(.00)$ & $2.0 \pm 0.0 *(1.02)$ \\
\hline \multirow[t]{2}{*}{ Hours missed per week } & $0.3 \pm 2.0$ & $2.2 \pm 6.3^{*}(-.41)$ & $0.0 \pm 0.0(.21)$ \\
\hline & $\mathrm{n}(\%, n)$ & $\mathrm{n}(\%, n)$ & $\mathrm{n}(\%, n)$ \\
\hline Total no. jobs left & $17(28.3)$ & $6(21.4, .024)$ & $1(50.0, .013)$ \\
\hline \multicolumn{4}{|l|}{ Reason for job ending } \\
\hline Quit & $2(11.8)$ & $2(33.3)^{*}$ & $0(0.0)$ \\
\hline Fired & $1(5.9)$ & $0(0.0)$ & $0(0.0)$ \\
\hline Laid off & $1(5.9)$ & $0(0.0)$ & $0(0.0)$ \\
\hline Seasonal/contract completed & $12(70.6)$ & $2(33.3)$ & $1(100.0)$ \\
\hline Other/unknown & $1(5.9)$ & $2(33.3, .48)^{*}$ & $0(0.0)^{+}$ \\
\hline
\end{tabular}

NOTE. Values are mean \pm SD or $\mathrm{n}(\%)$. No percentages (NA) are given for Total jobs, as subjects were allowed to have multiple jobs and there is no expressed denominator. Effect sizes for the comparison of SE vS TAU-IS and SE vS TAU-OS are Cohen's $d$ or Cramer's $V$, where appropriate. A separate comparison of "Quit" as the stated reason for job ending between SE and TAU-IS groups was performed using a $\chi^{2}$. The Wilcoxon rank-sum test was used to test wages due to the observed nonparametric distribution. Abbreviation: NA, not applicable.

* Statistically significant association between SE and TAU-IS (Student $t$ test or $\chi^{2}, P<.05$ ).

${ }^{+}$Statistically significant association between SE and TAU-OS (Student $t$ test or $\chi^{2}, P<.05$ ).

Analyses comparing the 3 groups on wages earned and hours worked and job endings were restricted to participants who obtained competitive work or any paid work. For these subjects, who obtained paid employment postbaseline, their wages earned per week and their hours worked were analyzed by treatment group (table 4). Subjects in the SE group earned significantly less per week than subjects in the TAU-IS group $(\$ 233.9 \pm 279.0$ vs $\$ 267.3 \pm 462.5, P<.000)$ but significantly more than those in the TAU-OS group $(\$ 233.9 \pm 279.0$ vs $\$ 150.0 \pm 0.0, P<.208)$. Subjects in the SE group worked significantly more hours per week $(22.0 \pm 14.6)$ than those in the TAU-IS group $(17.0 \pm 14.6, P<.000)$, but not those in the TAU-OS group $(16.0 \pm 0.0, P<.489)$.

The mean duration $\pm \mathrm{SD}$ of the 90 jobs was $19.9 \pm 14.7$ weeks. Of those 90 jobs, 24 were ended for the following reasons: seasonal or contract with the customer completed $(n=15,62.5 \%)$, quit $(n=4,16.7 \%)$, fired $(n=1,4.2 \%)$, and other reason $(n=3$, $54.2 \%$ ). Forty-seven job categories were identified ranging from general labor to health/leisure. The most common job types were general labor $(21.3 \%)$, clerical $(17 \%)$, and sales $(12.8 \%)$. There were 80 documented instances of missed work. More than half were attributable to medical issues $(56.3 \%)$, followed by nonmedical extraneous reasons $(15.0 \%)$, family problems $(18.8 \%)$, leisure time $(7.5 \%)$, and transportation problems $(2.5 \%)$. Among documented medically related instances of missed work, primary reasons listed were leg and back pain $(46.7 \%)$, cellulitis (17.8\%), and illness $(8.9 \%)$. No subjects reported pressure ulcers or urinary tract infections as reasons for missed work. Bowel issues were not listed as a separate category among the response options for reasons for missed work, although no subjects listed bowel-related issues when specifying "other" reasons for missing work.

\section{Comparison of Treatment Groups on Employment: Intent to Treat}

The analyses comparing all groups on wages earned and hours worked were then expanded to include all participants regardless of whether they obtained competitive work or any paid work. When all subjects are considered, subjects in the SE group $(n=81)$ earned more per week than subjects in the TAU-IS group $(\$ 69.3 \pm 209.3$ vs $\$ 31.7 \pm 325.1, P<.387)$, although this difference was not significant. However, subjects in the SE group did earn significantly more per week than subjects in the TAU-OS group $(\$ 69.3 \pm 209.3$ vs $\$ 6.8 \pm 0.0, P<.001)$. Subjects in the SE group worked significantly more hours per week $(6.5 \pm 1.5)$ than subjects in both the TAU-IS group $(2.0 \pm$ $1.6, P<.001)$ and the TAU-OS group $(0.7 \pm 0.0, P<.001)$.

The rate of competitive employment to any paid employment was $80.1 \%$ (ie, 72 of 90 jobs were competitive employment) for the study as a whole. Among the sites, 2 interventional sites with competitive employment rates of $84.6 \%$ (22/ 26) and $89.5 \%(34 / 38)$ clearly contrasted with the remaining sites that had competitive employment rates that ranged between $62.5 \%(15 / 24)$ and $50.0 \%(1 / 2)$. Not surprisingly, sites with higher competitive employment rates demonstrated higher wages per week (Kruskal-Wallis $\chi^{2}=7.6, P<.056$ ) and hours worked per week (Kruskal-Wallis $\chi^{2}=18.5, P<.000$ ).

\section{DISCUSSION}

This study demonstrated that SE was more effective than standard vocational care in improving employment outcomes for veterans with SCI who wished to return to work. Veterans with SCI who received SE services were significantly more likely to return to work than those who were referred outside the SCI centers for standard VR services. To the best of our knowledge, this is the first and only study to demonstrate that persons with serious physical disabilities, namely SCI, can benefit from SE approaches.

Veterans who received SE were 2.5 times more likely to achieve employment than those who received TAU, which may have included referral to conventional VR services, at interventional sites. When veterans who received SE are compared with those who had no exposure to SE in their SCI centers (the TAU-OS group), they were over 10 times more likely to achieve employment. It is quite likely, and consistent with our 
clinical observations, that the presence of SE in the treatment setting elevated the awareness and attention to vocational issues and outcomes in general. At centers where SE was offered, the clinical providers were more likely to ask their patients about employment status and interest level in pursuing VR, whereas in centers where only standard care was in place, it is unlikely that there was a detectable change in provider behavior related to vocational issues. This finding supports the positive effects of having a vocational program in place within the setting where patients with SCI receive their care.

To our knowledge, there are no other published studies on employment rates for persons with SCI after VR programs. This study demonstrates that 1 method of VR, SE, which follows a well-prescribed and intensive method service delivery, has utility within the medical rehabilitation setting. Given the complexity of issues and barriers faced by individuals with SCI, there may be many reasons why SE has benefits for this population over conventional methods of VR. For one, this model involves integrating vocational services within the medical rehabilitation health care setting. This integration meant that the interdisciplinary health care team, which included the VR specialist, could identify and address barriers with the veterans as they began a job search, as well as after the job was obtained and new issues emerged. In more traditional models of VR, a referral to an outside VR service provider is made at the conclusion of the care episode, with little linkage between VR and the teams that address the health care needs of persons with SCI.

Our study did not compare SE to another new model of VR. Our intention, rather, was to compare a novel method of VR, SE, with typical practice. It has been our observation that when veterans are referred to providers or agencies outside the SCI center, relatively few of them actually receive any VR services. This is supported by our study finding that veterans in the SE group had twice as many VR visits than those who were referred outside the SCI center for vocational care. This observation would seem to suggest that there are issues that impact successful access to VR for persons with SCI that negatively affect service provision and thereby outcomes. It may be that if veterans are able to access and receive an adequate amount of vocational care, those services would be helpful in returning them to work as long as they are an integral part of their overall health care or treatment plan. This line of reasoning is worthy of more focused investigation.

The employment rate of veterans with SCI receiving SE in this study does not reach the employment rates reported for persons with SMI (see Introduction). There could be several possible explanations for these findings, including differences in populations, fidelity of the experimental condition, timing of services, or a combination of these factors. Perhaps the most obvious would be that this is attributable to the distinctions between these populations. Veterans with SCI may have co-occurring mental illness, traumatic brain injury, substance abuse, homelessness, and possibly a history of legal problems. However, they have multiple significant additional challenges related to their SCI. These may include bowel and bladder dysfunction with possible incontinence, risk for pressure ulcers, neuropathic pain syndromes, impaired mobility requiring wheelchair or other assistive devices, and impaired arm function. With the assumption that the EBP-SE model is disability neutral in mind, the experimental design did not include or study any modifications to the model specific to the SCI population. More research is needed before attributing differences in outcomes to population-specific factors.

There is reason to suspect that the lower employment rates are attributable to the less than optimal implementation of the SE model in this novel population than in populations where the model has been established and widely practiced over the years. The study was able to achieve fair SE implementation applying SE principles for the first time, to the best of our knowledge, in the SCI setting, meaning there was partial implementation of the SE principles. Since high fidelity (ie, full implementation) has been consistently linked to higher employment outcomes in the mental health population, ${ }^{32}$ it could be that with further experience and penetration of the model into the SCI system of care, both higher fidelity and associated higher outcomes would be achieved. Further implementation and research are needed to draw conclusions here, but the findings are encouraging in terms of looking toward the future for improving outcomes with better implementation in this population.

Finally, the present study's sample was largely a chronic SCI population who had been living with both SCI and unemployment for many years. Our preliminary baseline data from this ongoing trial indicate that most $(72 \%)$ of our sample of employment-seeking veterans with SCI had never been employed postinjury, a figure that is consistent with the low rates of employment found in community samples of persons with SCI. It would be interesting to see whether better outcomes are achieved when SE is offered closer to the time of the initial injury, before social disenfranchisement and reliance on disability benefits become a more ingrained pattern of living.

In our study, most employment outcomes comprised part-time jobs with earnings that would be considered less than substantial gainful activity by Social Security definitions. At this exploratory stage of model use in this population, we established no a priori targets for defining successful employment and attempted to be consistent with the SE principle of consumer choice in regards to the goals for both the type and amount of work preferred by the veteran participants. Anecdotally, we know there were some cases where participants clearly voiced to their VR counselor that they preferred to work only a minimum number of hours because they did not want to lose their Social Security benefits. With most of the sample receiving Social Security benefits, veterans benefits, or both, there would be a significant financial disincentive for them to pursue full-time employment. In the case of Social Security Disability Insurance for example, individuals may only work for 9 months earning above substantial gainful activity before benefits are jeopardized. Assisting a group with such a severe disability and heavy reliance on subsidy was anticipated to be challenging in reaching any level of employment outcomes. We acknowledge that this level of employment, being less than full-time work with low earnings, may not be representative of the optimum level of employment outcomes that could be achieved with better implementation of the evidence-based SE model in SCI. We also feel that further investigation of outcomes in relation to benefit status may elucidate what meaningful and attainable employment goals can be anticipated for various groups of veterans with SCI.

\section{Study Limitations}

Potential limitations of this study include the study population, definition of employment, and geographic regions selected for enrollment. The study included primarily male veterans, who may or may not be reflective of the general SCI population regarding potential for employment. It is possible that the experience of women with SCI may not be accurately represented by our study outcomes. Our study population was recruited within large urban centers where transportation may be easier and employment opportunities may be better for individuals with SCI than in more rural areas. Therefore, our results may not be generalizable to all veterans with SCI. Additionally, although our study design used a randomized, controlled trial approach, the second control group was not randomly assigned. Comparisons made between TAU-OS subjects and SE subjects should be interpreted in this light. Although lacking in power to perform a fully stratified analysis, site 
variation for the primary outcome "competitive employment" among randomly assigned SE participants was noted. Furthermore, there was a difference in the amount of vocational services received by the SE versus the TAU groups. This was most likely a reflection of differences in the paradigm of care between groups. The SE model is a more intensive, individualized, and integrated model of care compared with the TAU groups. We sought to adhere as closely as possible to real-world conditions for this field trial and not artificially alter the TAU condition, but it could be that more vocational care, regardless of the model used, could have resulted in improved outcomes. We believe this merits further investigation, but maintain that integrated and individualized services are likely a critical component of program success.

\section{CONCLUSIONS}

SE was shown to be an effective means of improving employment outcomes among veterans with SCI as compared with standard care that involved referrals to VR outside the SCI centers. This finding argues strongly for integrating VR within the medical rehabilitation setting for veterans with SCI. Further research is warranted to investigate issues that are likely related to VR outcomes, including improving access to services as well as the optimal timing and intensity of services.

Acknowledgments: We acknowledge the contributions of our team of research coordinators. We thank the CWT program managers and VR clinicians, as well as the Paralyzed Veterans of America and Work Incentives Planning and Assistance benefits counselors, whose expertise served the veteran participants of this study.

\section{References}

1. Ottomanelli L, Lind L. Review of critical factors related to employment after spinal cord injury: implications for research and vocational services. J Spinal Cord Med 2009;32:315-31.

2. Erickson W, Lee C. Disability status report: United States. Ithaca: Cornell University Rehabilitation Research and Training Center on Disability Demographics and Statistics; 2008.

3. Krause JS, Anson CA. Employment after spinal cord injury: relation to selected participant characteristics. Arch Phys Med Rehabil 1996;77:737-43.

4. El Ghatit AZ, Hanson RW. Variables associated with obtaining and sustaining employment among spinal cord injured males: a follow-up of 760 veterans. J Chronic Dis 1978;31:363-9.

5. Deyoe FS Jr. Spinal cord injury: long-term follow-up of veterans. Arch Phys Med Rehabil 1972;53:523-9.

6. Dew MA, Lynch K, Ernst J, Rosenthal R. Reaction and adjustment to spinal cord injury: a descriptive study. J Appl Rehabil Counsel 1983;14:32-9.

7. Ottomanelli L, Goetz LL, Sippel J, Cipher D. Factors associated with employment among veterans with spinal cord injury. J Vocat Rehabil 2011:34:141-50.

8. Tomassen PC, Post MW, van Asbeck FW. Return to work after spinal cord injury. Spinal Cord 2000;38:51-5.

9. Young AE, Murphy GC. A social psychology approach to measuring vocational rehabilitation intervention effectiveness. J Occup Rehabil 2002;12:175-89.

10. Krause JS, Sternberg M, Maides J, Lottes S. Employment after spinal cord injury: differences related to geographic region, gender, and race. Arch Phys Med Rehabil 1998;79:615-24.

11. Rehabilitation Act Amendments of 1986, Pub L No. 99-506, Washington, DC, 99th Congress, 1986.

12. Rehabilitation Act Amendments of 1992, Pub L No. 102-569, Washington, DC, 102nd Congress, 1992.
13. Becker DR, Drake RE. Supported employment interventions are effective for people with severe mental illness. Evid Based Ment Health 2006;9:22.

14. Bond GR, Becker DR, Drake RE, et al. Implementing supported employment as an evidence-based practice. Psychiatr Serv 2001; 52:313-22.

15. Bond GR. Supported employment: evidence for an evidencebased practice. Psychiatr Rehabil J 2004;27:345-59.

16. Bond GR, Drake RE, Becker DR. An update on randomized controlled trials of evidence-based supported employment. Psychiatr Rehabil J 2008;31:280-90.

17. Resnick SG, Rosenheck R. Dissemination of supported employment in Department of Veterans Affairs. J Rehabil Res Dev 2007; 44:867-78.

18. Rosenheck RA, Mares AS. Implementation of supported employment for homeless veterans with psychiatric or addiction disorders: two-year outcomes. Psychiatr Serv 2007;58:325-33.

19. Bond G. Modest implementation efforts, modest fidelity, and modest outcomes. Psychiatr Serv 2007;58:334.

20. Inge K, Wehman P. Supported employment and assistive technology for persons with spinal cord injury: three illustrations of successful work supports. J Vocat Rehabil 1998;10:141-52.

21. Targett P, Wehman P. Successful work supports for persons with spinal cord injury. Psychosoc Process 2003;16:1-11.

22. Wehman P, Booth M, Stallard D, et al. Return to work for persons with traumatic brain injury and spinal cord injury: three case studies. Int J Rehabil Res 1994;17:268-77.

23. Ottomanelli L, Goetz LL, McGeough C, et al. Methods of a multi-site randomized clinical trial of supported employment among veterans with spinal cord injury. J Rehabil Res Dev 2009; 46:919-30.

24. Efron B. Forcing a sequential experiment to be balanced. Biometrika 1971;58:403-17.

25. Kazis LE. The Veterans SF-36 Health Status Questionnaire: development and application in the Veterans Health Administration. Med Outcomes Trust Monitor 2000;5:1-18.

26. Rush AJ, Trivedi MH, Ibrahim HM, Carmody TJ, Arnow B, Klein DN. The 16-Item Quick Inventory of Depressive Symptomatology (QIDS), Clinician Rating (QIDS-C), and Self-Report (QIDS-SR): a psychometric evaluation in patients with chronic major depression. Biol Psychiatry 2003;54:573-83.

27. Whiteneck GG, Charlifue SW, Gerhart KA, Overholser JD, Richardson GN. Quantifying handicap: a new measure of long-term rehabilitation outcomes. Arch Phys Med Rehabil 1992;73:519-26.

28. Bond GR, Becker DR, Drake RE, Vogler KM. A fidelity scale for the individual placement and support model of supported employment. Rehabil Couns Bull 1997;60:265-84.

29. Bond GR, Vogler KM, Resnick SG, Evans LJ, Drake RE, Becker DR. Dimensions of supported employment: factor structure of the IPS Fidelity Scale. J Ment Health 2001;10:383-93.

30. Marino R, Ditunno JF, Donovan WH, et al, editors. International standards for neurological classification of spinal cord injury. 5th ed. Chicago: American Spinal Injury Association; 2000. p 1-23.

31. Go BK, DeVivo MJ, Richards JS. The epidemiology of spinal cord injury. In: Stover S, Delisa JA, Whiteneck GG, et al, editors. Spinal cord injury: clinical outcomes from the Model Systems. Gaithersburg: Aspen Publishers; 1995. p 21-55.

32. Bond GR, Becker DR, Drake RE. Measurement of fidelity of implementation of evidence-based practices: case example of the IPS Fidelity Scale. Clin Psychol Sci Prac 2011;18:126-41.

\section{Supplier}

a. SAS Institute Inc, 100 SAS Campus Dr, Cary, NC 27513. 